\title{
Abnormal Chemosensory Jump 6 Is a Positive Transcriptional Regulator of the Cholinergic Gene Locus in Drosophila Olfactory Neurons
}

\author{
Mi-Heon Lee and Paul M. Salvaterra \\ Division of Neuroscience, Beckman Research Institute of the City of Hope, Duarte, California 91010
}

Cholinergic neurons acquire their neurotransmitter phenotype, in part, by expressing the cholinergic gene locus. Previous studies have indicated that the $5^{\prime}$ flanking DNA of the locus contains both positive and negative regulatory elements important for expression in different subsets of cholinergic neurons in Drosophila and other animals. Approximately 300 bases of proximal 5' flanking DNA control expression in Drosophila CNS neurons essential for viability, whereas more distal regulatory elements are important for expression in PNS sensory neurons. In this study we identify the POU domain transcription factor abnormal chemosensory jump 6 (Acj6) as a necessary positive transcriptional regulator for cholinergic locus expression in primary olfactory neurons. Choline acetyltransferase enzyme activity, protein levels, mRNA, and a fluorescent cholinergic reporter gene are all decreased in olfactory neurons of acj6 mutants. Decreased cholinergic expression was observed in both adults and larvae. The presence of a specific Acj6 binding site has been identified in the cholinergic locus 5' flanking DNA, suggesting that Acj6 may play a direct role in specifying the cholinergic neurotransmitter phenotype of most olfactory neurons. Transgenic expression of two different isoforms of Acj6 restricted to olfactory neurons indicates that additional trans factors may be required for cholinergic locus expression. Transgenic expression in all cholinergic neurons, however, results in lethality when a POU IV box element is absent but is essentially benign when present, indicating the importance of this motif in specifying different functional roles for Acj6.

Key words: cholinergic locus; POU domain transcription factor; POU IV box; Acj6; neurotransmitter phenotype; olfactory neurons
Expression of particular neurotransmitter phenotypes is a key component of neurons and an important organizational principle of the nervous system necessary to establish proper communication among cells in neural networks and ensembles. Neurons using classical small molecule neurotransmitters attain their phenotypes by regulating specific genes that catalyze the unique biosynthesis of transmitter and unique uptake systems for packaging neurotransmitter into synaptic vesicles or recovering transmitter by plasma membrane uptake. Many specific neurotransmitter-related genes are controlled by transcriptional regulatory elements present in their 5' flanking DNA (Kitamoto et al., 1992, 1995; Kitamoto and Salvaterra, 1993, 1995; Quinn et al., 1995; Hahm et al., 1997; Benveniste and Taghert, 1999; Sacchetti et al., 1999).

Acetylcholine is an important neurotransmitter in all animals, and cholinergic neurons can be recognized by expression of the uniquely organized cholinergic gene locus (Usdin et al., 1995). This complex locus encodes two essential functions for cholinergic neurotransmission: choline acetyltransferase (ChAT) and the vesicular acetylcholine transporter (VAChT) (Alfonso et al., 1993; Erickson et al., 1994; Kitamoto et al., 1998). Transgenic

\footnotetext{
Received Jan. 16, 2002; revised April 4, 2002; accepted April 10, 2002.

This work was supported by grants from National Institutes of Health-National Institute of Neurological Disorders and Stroke and the John Douglas French Foundation for Alzheimer's Research. We thank Dr. E. Turner for providing recombinant Acj6 protein, Drs. P. Clyne and J. R. Carlson for acj6 mutants, and Dr. Wayne Johnson for the UAS-acj6 and GH86-Gal4 lines. We also thank R. Williamson for generously providing expert genetic advice, Drs. T. Kitamoto, S. Song, and N. Bournias-Vardiabasis for helpful discussions, and Elvia Guiterrez for excellent technical assistance.

Correspondence should be addressed to Paul M. Salvaterra, Division of Neuroscience, Beckman Research Institute of the City of Hope, 1450 East Duarte Road, Duarte, CA 91010. E-mail: psalv@coh.org.

Copyright (C) 2002 Society for Neuroscience $\quad 0270-6474 / 02 / 220001-09 \$ 15.00 / 0$
}

animals containing parts of the cholinergic locus 5' flanking DNA fused to reporter genes show subset specific expression patterns (Kitamoto et al., 1992, 1995; Kitamoto and Salvaterra, 1993; Yasuyama et al., 1995; Naciff et al., 1999; Yasuyama and Salvaterra, 1999). In Drosophila, the regulatory control also appears to be independent in some types of cholinergic neurons such as peripheral sensory neurons (Kitamoto et al., 1992; Kitamoto and Salvaterra, 1993, 1995; Yasuyama et al., 1995). These previous results imply that regulation of the cholinergic locus is different in different types of cholinergic neurons and that vertebrates and insects may share a common regulatory strategy (Kitamoto et al., 1998). Few cis-regulatory elements and associated trans factors, however, have been identified that would be candidates for differential regulation (Hahm et al., 1997; Berse et al., 1999; De Gois et al., 2000). The Drosophila POU domain protein Nubbin (also known as Pdm1) is important for cholinergic locus expression in CNS neurons essential for survival (Kitamoto and Salvaterra, 1995), but cis and trans factors important for other types of cholinergic neurons, such as PNS sensory neurons, are unknown.

Drosophila offers a favorable genetic system to identify transcriptional regulators for different types of cholinergic neurons. We have recently described a fluorescent cholinergic reporter system that allows identification of cholinergic neurons in live animals (Salvaterra and Kitamoto, 2001) which was used in this study. Here, we show that expression of the cholinergic locus in olfactory neurons is decreased in mutants of the abnormal chemosensory jump 6 (acj6, also known as IPOU) gene. Acj6 is a class IV POU domain transcription factor homologous to members of the vertebrate Brn3 family (Treacy et al., 1991) and is required for normal olfactory physiology and behavior in both larval and adult Drosophila (McKenna et al., 1989; Ayer et al., 1991; Ayer 
and Carlson, 1992; Clyne et al., 1999a; Certel et al., 2000). A specific Acj6 binding motif has also been demonstrated in an appropriate part of the cholinergic regulatory DNA. Our results lead us to propose that Acj6 may be a direct transcriptional regulator of the cholinergic locus in PNS olfactory sensory neurons and that abnormal cholinergic synaptic transmission could explain many of the acj6 mutant phenotypes.

\section{MATERIALS AND METHODS}

Fly culture and transgenic lines. Drosophila melanogaster Canton S-5 (CS-5), the parental wild-type strain from which acj6 mutants were derived (McKenna et al., 1989), were reared at 18 or $25^{\circ} \mathrm{C}$ on cornmeal, sucrose, yeast media.

The olfactory neuron-specific P [Gal4] driver line GH86 (Heimbeck et al., 1999) and the UAS-Acj6 (1,3,4) and UAS-Acj6 $(1,4)$ (Certel et al., 2000) responder lines were obtained from Dr. W. A. Johnson (University of Iowa). UAS-Acj6 $(1,3,4)$ (chromosome II) and UAS-Acj6 $(1,4)$ (chromosome III) transgenic lines (Certel et al., 2000) were recombined with Cha-Gal4 lines (chromosome III or II) by standard genetic crosses using second or third chromosome balancers, $\mathrm{CyO}$ or TM3. The GH86 olfactory driver was recombined with either UAS-Acj6 $(1,3,4)$ or UAS-Acj6 $(1,4)$ transgenic lines, and male progeny were used for ChAT assay (see below).

A fluorescent cholinergic reporter line marking essentially all known cholinergic neurons consisted of a $7.4 \mathrm{~kb}$ Cha-Gal4 driver line (19B) recombined with UAS-GFP (S65T) and has been described previously (Salvaterra and Kitamoto, 2001). The 19B driver (chromosome II) and another $7.4 \mathrm{~kb}$ Cha-Gal4 line (15A, chromosome III) were used to drive expression of UAS transgenes. A new $1.2 \mathrm{~kb}$ Cha-Gal4 line was constructed for this study by PstI digestion of 1.2 Cha-pCaSpeR-AUG- $\beta$-gal (Kitamoto et al., 1995). The resulting digest was blunt-ended with T4 polymerase and further digested with BamHI to remove the $\beta$-gal sequence. The vector was then ligated to a Gal4 fragment (5' blunt-ended by Klenow digestion) obtained from pGaTB (Brand and Perrimon, 1993) by SpeI/Bam HI digestion. This construct was microinjected into embryos using standard methods (Rubin and Spradling, 1982). Transformant lines (1.2 kb Cha-GAL4) were recombined with UAS-GFP lines (Bloomington Stock Center) and characterized for their fluorescence expression pattern using standard fluorescence microscopy (see below).

Mutant stocks. We obtained $a c j 6^{1}$ and $a c j 6^{6}$ from Drs. Peter J. Clyne and J. R. Carlson (Yale University). acj6 $6^{1}$ is a homozygous stock. acj6 $6^{6}$ males were maintained with $C(1) A, y / Y$ females. $l z^{3}$ males maintained with $C(1) D X, y f / Y$ females were obtained from the Bloomington Stock Center. Descriptions are found in Lindsley and Zimm (1992) and on line at FlyBase (http://flybase.bio.indiana.edu). A acj $\sigma^{6} / C(1) A / Y ; 7.4$ ChaGal4 UAS-GFP stock was constructed from $a c j 66 / Y ; 7.4$ Cha-Gal4 UAS$\mathrm{GFP} /+$ males mated to $C(1) A, y / Y ;+/ \mathrm{SM} 5, \mathrm{Cy}$ females. F1 fluorescent curly winged offspring were selected and mated to produce strongly fluorescent normal winged $\mathrm{F} 2$ flies used for the stock. $l z^{3} / \mathrm{Y}$ males were mated to $C(1) D X / Y ; 7.4$ Cha-Gal4 UAS-GFP females. Strongly fluorescent flies were selected from the F2 generation for the purpose of mating in single pairs. A $l z^{3} / C(1) D X, y f / Y ; 7.4$ Cha-Gal4 UAS-GFP true breeding stock was selected from among F3 offspring.

Microscopy. Larvae were washed out of their food with a $15 \%$ sucrose solution and rinsed two times in PBS. Adult antennae or maxillary palps were dissected from male heads in PBS. Larvae or adult appendages were fixed for $30 \mathrm{~min}$ in $3.7 \%$ formaldehyde in PBS and mounted directly under a coverslip in a solution of $50 \%$ glycerol in PBS, pH 7.4. Adult brains were first removed in cold PBS, fixed, and mounted as above. Green fluorescent protein (GFP) fluorescence was observed by either confocal or wide-field fluorescence microscopy. Confocal microscopy used a Zeiss LSM 310. Excitation was at $488 \mathrm{~nm}$ (argon laser) and emission at $515 \mathrm{~nm}$. Z-sections were collected and processed using Scion IMAGE (Scion, Frederick, MD) to construct three-dimensional rotating projections or maximum intensity projections through an extended depth of focus. Processing involved minor corrections of brightness and contrast. Wide-field fluorescence observations were made with an Olympus AX70 microscope using the U-MNB filter cube (excitation 470-490 nm, emission $515 \mathrm{~nm}$ ). Images (12 bit) were collected with a Real14 CCD camera (Cambridge Research Instruments, Cambridge, MA) and processed using Image Pro Plus (Media Cybernetics, Silver Springs, MD) or Photoshop (Adobe, San Jose, CA). Processing consisted of minimally correcting light levels, contrast, and brightness, and digital merging.

ChAT enzyme assay. ChAT activity was assayed using a standard method (Fonnum, 1975) as described previously (Kitamoto et al., 1992). Adult flies were homogenized in $40 \mu \mathrm{l}$ per fly of $50 \mathrm{~mm}$ Tris-HCl, $0.1 \mathrm{M}$ $\mathrm{NaCl}, 0.5 \%$ Triton $\mathrm{X}-100, \mathrm{pH} 7.5$, on ice. The samples were frozen and thawed once and centrifuged for $10 \mathrm{~min}$ at $4^{\circ} \mathrm{C}$. The supernatant $(20 \mu \mathrm{l})$ was incubated with an equal volume of ${ }^{14} \mathrm{C}$-labeled acetyl-CoA enzyme substrate at $37^{\circ} \mathrm{C}$ for $10 \mathrm{~min}$.

Western blot. For Western blot analysis (Harlow and Lane, 1988) of ChAT protein, 10 heads from males of appropriate genotype were homogenized in SDS-dissociation buffer (50 mM Tris-HCl, $\mathrm{pH}$ 8.0, $0.1 \mathrm{M} \mathrm{NaCl}$, $5 \%$ SDS, $1 \mathrm{~mm}$ ethylenediamine tetraacetic acid, $1 \%$ 2-mercaptoethanol). The supernatant was obtained after centrifugation for $15 \mathrm{~min}$ at 12,000 $\mathrm{rpm}$. One hundred micrograms of total protein were electrophoresed on a $12 \%$ SDS-polyacrylamide gel and transferred to a nitrocellulose membrane for antibody staining. The nitrocellulose membrane was incubated with anti-Drosophila anti-ChAT monoclonal antibody 4B1 (1:1000) (Yasuyama et al., 1995). Antibody binding was detected with alkaline phosphataseconjugated goat anti-mouse IgG (Pierce; 1:5000), and color was developed using bromochloroindolyl phosphate/nitroblue tetrazolium solution. Parallel Coomassie blue-stained SDS-PAGE gels confirmed that similar amounts of protein were analyzed for each genotype.

$R T$-PCR. ChAT-specific RNA was estimated using a quantitative PCR procedure. One hundred antennae from either CS-5 or $a c j 6^{6}$ males were dissected and homogenized in $500 \mu \mathrm{l}$ of RNAzol B for total RNA extraction (Tel-Test, Friendswood, TX; RNAzol protocol). RT-PCR (Qiagen one-step RT-PCR kit; Qiagen, Valencia, CA) contained $200 \mathrm{ng}$ of total RNA, $1 \times$ buffer (kit), including $10 \mathrm{~mm}$ dNTPs, and enzyme along with $0.6 \mu \mathrm{M}$ primers [ChAT: forward 5'-GACGATGAACGACGAGGATCGC-3' (1162-1182), reverse 5'-TGCGGACCCACATGCCACTCC-3' (1780-1800); $\beta$-tubulin: forward 5'-GTCTCGCTGACC ATGTCCGGG-3' (822-842), reverse 5'-GCCTCTCGGCGGGATGTCG-3' (1199-1217)] in a final volume of $25 \mu$ l. The PCR was performed in a Robocycler (Stratagene, La Jolla, CA) at $50^{\circ} \mathrm{C}, 30 \mathrm{~min}$ for reverse transcription, $95^{\circ} \mathrm{C}, 15 \mathrm{~min}$ for initial PCR activation step, followed by $94^{\circ} \mathrm{C}, 1 \mathrm{~min}, 60^{\circ} \mathrm{C} 1 \mathrm{~min}, 72^{\circ} \mathrm{C} 1 \mathrm{~min}$, for 30 cycles. Amplified products were separated and analyzed by agarose gel electrophoresis. RNase-free DNase (Promega, Madison, WI) treatment was accomplished before RT-PCR reaction to avoid DNA contamination.

Gel mobility shift assay. We scanned the 5' flanking DNA of the cholinergic locus known to be important for PNS expression [3.3 kb minus $1.2 \mathrm{~kb}$ (Kitamoto et al., 1995)] and identified seven sites containing either an ATAATT or ATAAAT motif. These motifs are present in either of the two proposed DNA binding sites for Brn-3: ATAATTAAT or GCATAAATAA (Thompson et al., 1987; Gerrero et al., 1993; Turner et al., 1994; Gruber et al., 1997). Brn3 is the vertebrate homolog of Acj6 (Gerrero et al., 1993; Xiang et al., 1993). Potential Drosophila sites tested for Acj6 binding, in their proper flanking context, were as follows: (A) 485-5' -TTACAAATAATTTGAACTTCA-3', (B) 697-5' -ATAAGACATAATTGACA ATGGA-3', (C) 1133-5'-TGCCATATAATTTGGC-

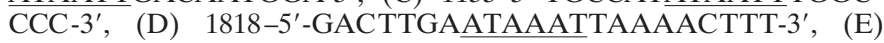
1959-5'-GATCTTAACATAATTCTGTGG-3', (F) 2001-5' -CTTGATAAATTGCAGAAGTGCT-3', and (G) 2028-5'-AGTGATAAATGACAATGAAAT- $3^{\prime}$. Numbers are relative to the $3.3 \mathrm{~kb}$ Cha $\overline{5^{\prime} \text { flanking }}$ DNA (see Fig. 7 for location of probe sequences). Complementary oligonucleotides (19-22 bases) were synthesized, end labeled with $\left[\gamma^{-32} \mathrm{P}\right]$ ATP using T4 polynucleotide kinase, and used as probes for gel electrophoretic mobility shift assays (EMSA). The EMSA binding mixture $(10 \mu \mathrm{l})$ contained $20 \mathrm{~mm}$ Tris, $\mathrm{pH} 8.0,100 \mathrm{~mm} \mathrm{KCl,} 5 \mathrm{mM} \mathrm{MgCl}_{2}, 2$ $\mathrm{mm}$ EDTA, $100 \mu \mathrm{g} / \mathrm{ml}$ poly(dI-dC), $100 \mu \mathrm{g} / \mathrm{ml} \mathrm{BSA}, 10 \%$ glycerol, $1 \mathrm{~mm}$ DTT, $\sim 90$ pmol of labeled DNA probe, and 50 ng of recombinant Acj6 protein composed of the POU-specific and POU homeodomains (Gruber et al., 1997). Recombinant Acj6 protein was obtained from Dr. Eric Turner (University of California, San Diego). Binding was at room temperature for $10 \mathrm{~min}$, and mixtures were then electrophoresed through $4 \%$ nondenaturing polyacrylamide gels at $4^{\circ} \mathrm{C}$. Gels were dried and bands were detected and quantified by Phosphorimager analysis (Molecular Dynamics/Amersham, Piscataway, NJ). The optimal Brn-3.0 recognition element, TGCATAATTAATTAC (Turner, 1996), was used as a positive control for Acj6 binding.

\section{RESULTS}

\section{Reduction of cholinergic locus expression in acj6 mutants}

ChAT enzyme activity was decreased in adult males containing either of two different acj6 mutant alleles. The decrease in en- 


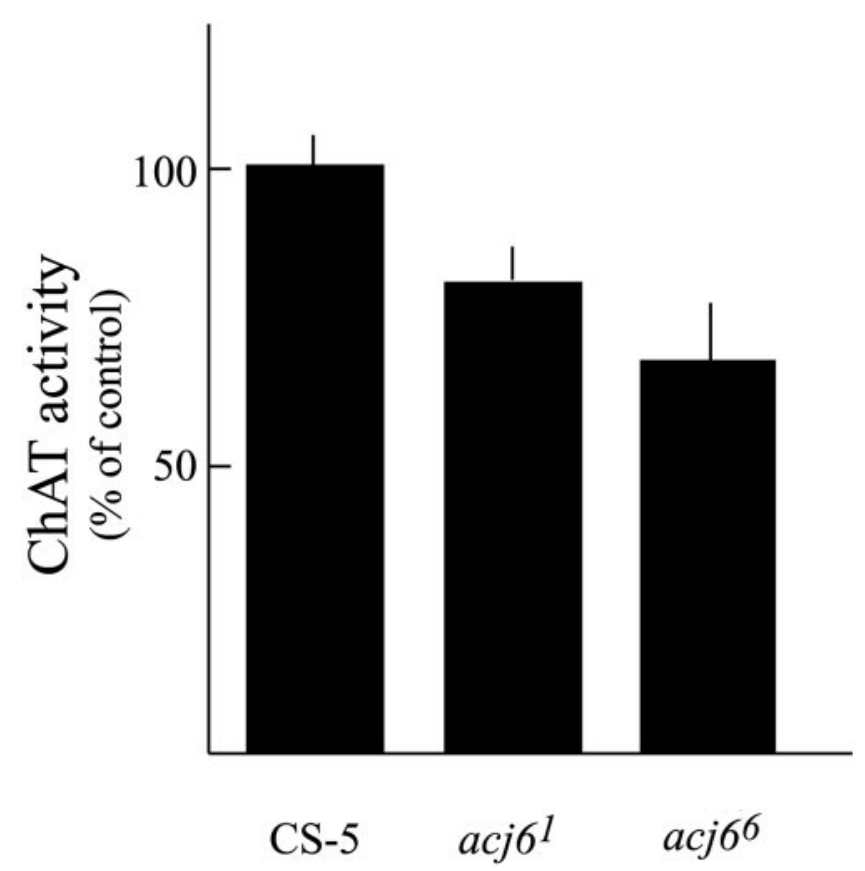

Figure 1. ChAT activity is reduced in $a c j 6^{1}$ and $a c j 6^{6}$ mutant males. Ten adult male flies (3-8 d old) of the indicated genotypes were homogenized, and the supernatants were assayed for ChAT activity. We observed a 20\% decrease in $\operatorname{acj}^{1}(p<0.0095)$ and a $34 \%$ decrease in $a c j 6^{6}(p<0.007)$ flies relative to wild type. Results are shown for three independent experiments in which enzyme activity $( \pm$ SEM) was determined in triplicate.

zyme activity was greater in the acj $6^{6}$ null allele $(\sim 34 \%)$ than in the $a c j 6^{1}$ hypomorphic allele $(\sim 20 \%)$ as shown in Fig. 1 . Western blots of protein extracts from $a c j 6^{6}$ mutant or wild-type male fly heads, stained with anti-ChAT antibody, indicate that the level of ChAT protein is also decreased in $a c j 6^{6}$ mutants as shown in Figure $2 A$. Because the same amount of total protein was added to each lane of the gel as shown Figure $2 B$, a decrease in ChAT protein production or an increase in its degradation could account for the decreased enzyme activity.

Acj6 (Clyne et al., 1999a; Certel et al., 2000) as well as ChAT and VAChT (Kitamoto et al., 1995; Yasuyama et al., 1995; Yasuyama and Salvaterra, 1999) are expressed in a partially overlapping and complex set of both PNS and CNS neurons. Because olfactory organs such as the antennae can easily be isolated form adult flies by simple dissection, we initially examined the levels of ChAT mRNA in whole antennae using quantitative RT-PCR. Antennae contain a mixture of primary olfactory sensory neurons located on the third segment (Siddiqi, 1983) and primary mechanosensory neurons located primarily on the second segment (Eberl et al., 2000). Both populations of cells include cholinergic neurons (Salvaterra and Kitamoto, 2001), but only the olfactory neurons express Acj6 (Clyne et al., 1999a; Certel et al., 2000). As shown in Figure $3 A$, the ChAT mRNA levels in antennae of male acj $6^{6}$ mutants are reduced $\sim 30 \%$ relative to wild type. In contrast, no significant difference in $\beta$-tubulin expression was observed between the genotypes (Fig. $3 B$ ).

\section{Cholinergic reporter gene fluorescence is decreased in olfactory neurons of acj6}

We next examined cholinergic expression in acj6 mutants using a cholinergic fluorescent reporter line (Salvaterra and Kitamoto, 2001). The reporter line was constructed by fusing the complete

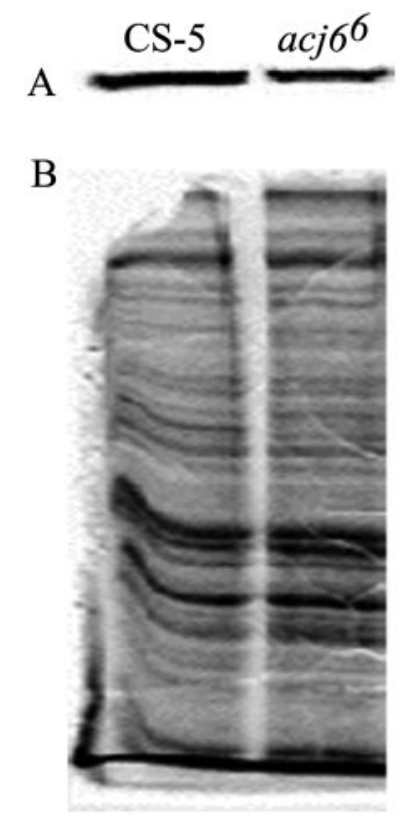

Figure 2. ChAT protein levels are reduced in acj6 $6^{6}$ mutant males. Protein extracts from adult males (3-8 d old) of the indicated genotypes were electrophoresed on SDS-polyacrylamide gels. $A$, Proteins were transferred to nitrocellulose, and ChAT protein was detected by immunostaining with anti-Drosophila ChAT monoclonal antibody 4B1. Only a single positive band was detected, and the intensity was reduced $\sim 66 \%$ for $a c j 6^{\circ}$ relative to wild type. $B$, A parallel gel stained with Coomassie blue shows that equal amounts of protein were loaded on the gels for each genotype.

A

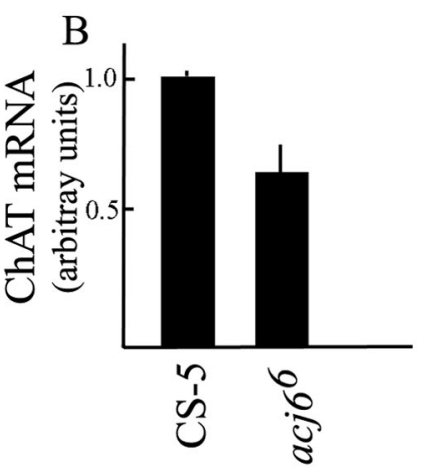

Figure 3. ChAT mRNA levels are reduced in antennae from acj6 $6^{6}$ mutant males. Total RNA was extracted from dissected antennae of 5- to 10 -d-old male flies. Samples were analyzed for ChAT or $\beta$-tubulin mRNA levels by ethidium bromide staining after RT-PCR. $A$, The ChAT-specific band $(693 \mathrm{bp})$ shows a dramatic reduction in samples from acj $6^{6}$ males relative to wild type. The $\beta$-tubulin band (396 bp) was similar for either genotype. $B$, Relative ChAT mRNA in CS-5 and $a c j 6^{6}$ mutant antennae. The levels of ChAT or $\beta$-tubulin mRNA bands were quantified from ethidium bromide-stained gels using Quantity One software (Bio-Rad, Hercules, CA). The height of the bars represents the mean mRNA values ( \pm SEM) for three independent experiments. ChAT mRNA was first normalized to the level of $\beta$-tubulin mRNA. ChAT mRNA values are significantly different for these two genotypes ( $t$ test; $p<0.005)$.

cholinergic locus regulatory DNA ( $\sim 7.4 \mathrm{~kb}$ of $5^{\prime}$ flanking sequence) to the yeast transcriptional activator Gal4 (Kitamoto, 2001). When this driver is recombined with UAS-GFP (S65T) responder line, all of the known cholinergic neurons exhibit bright GFP fluorescence (Salvaterra and Kitamoto, 2001). As shown in Figure $4 A$, robust cholinergic reporter gene expression is easily observed in the primary olfactory neurons localized to 

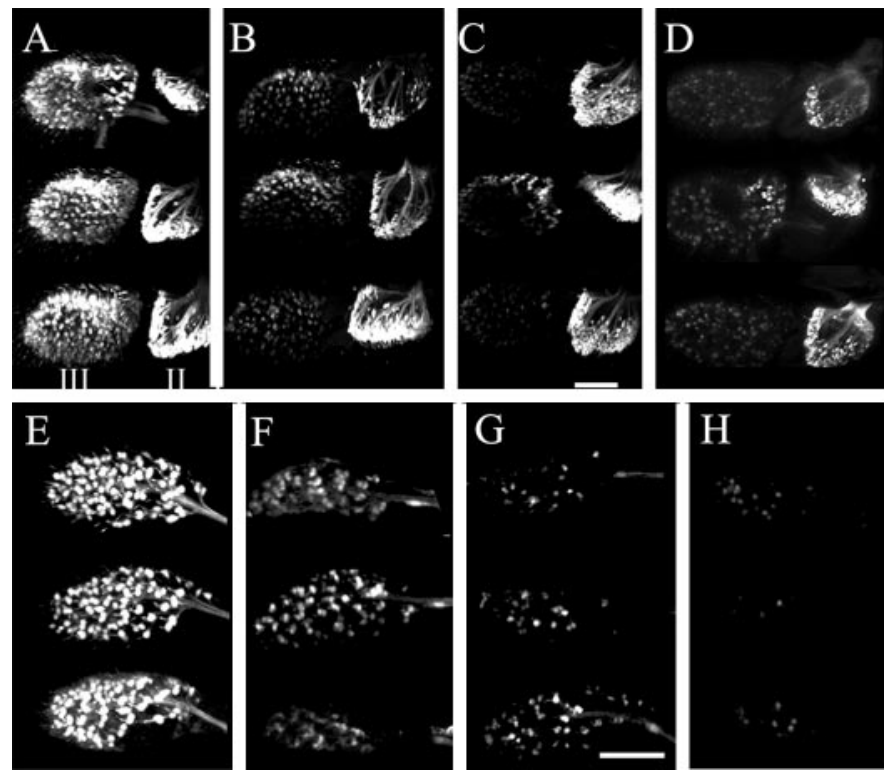

Figure 4. Expression of a cholinergic neuron reporter gene is decreased in primary olfactory neurons of antennae and maxillary palps from $a c j 6^{6}$ mutant males. Antennae or maxillary palps were dissected from the heads of three different adult male flies containing a fluorescent cholinergic reporter gene system and imaged using confocal microscopy. Stacks of Z sections were collected, and two-dimensional (2D) projections were constructed to provide an extended depth of focus. $A$, Numerous primary olfactory neurons are visible in the third antennal segment (III) of wild-type flies containing a $7.4 \mathrm{~kb}$ Cha-Gal4/ UAS-GFP reporter system marking all cholinergic neurons. Chordotonal mechanosensory neurons are also intensely fluorescent in the second antennal segment $(I I)$. $B$, Most of the primary olfactory neuron fluorescence is lost from the third segment in antennae from acj6 6 mutant males containing the $7.4 \mathrm{~kb} C h a-G a l 4 / \mathrm{UAS}-\mathrm{GFP}$ reporter. The second segment fluorescence appears normal. $C$, Nearly all fluorescence is absent from the third segment of antennae from $l z^{3}$ mutants, and the segment is smaller than that of $a c j 6^{6}$ or wild-type flies. The second segment fluorescence appears normal. $D$, Nearly all third segment fluorescence is lost in wild-type flies containing a $1.2 \mathrm{~kb}$ Cha-Gal4/UAS-GFP fluorescent reporter system. The second segment fluorescence appears relatively normal. $E$, Most primary olfactory neurons in maxillary palps from wild-type flies containing a $7.4 \mathrm{~kb}$ Cha-Gal4/UAS-GFP reporter system are fluorescent. We count $97 \pm 1$ $(\mathrm{SEM} ; n=5)$ cholinergic fluorescent neurons. $F$, The number and intensity of cholinergic fluorescent olfactory neurons are reduced in maxillary palps from $a c j 6^{6}$ mutant males. $G$, The number and intensity of cholinergic fluorescent olfactory neurons are reduced in maxillary palps from $l z^{3}$ mutant males. $H$, Nearly all cholinergic fluorescence is absent from maxillary palps from wild-type flies containing the $1.2 \mathrm{~kb}$ Cha-Gal4/UAS-GFP reporter system. All antennae are viewed from the dorsal surface with distal to the left and medial up. Scale bar, $50 \mu \mathrm{m}$.

the third segment of adult male antennae as well as the mechanosensory neurons of the second segment. In addition to the antennae, adult Drosophila has a second olfactory organ, the maxillary palps (Ayer and Carlson, 1992). Many olfactory neurons are intensely fluorescent in maxillary palps dissected from wild-type flies as shown in Figure $4 E$.

When the complete $7.4 \mathrm{~kb}$ Cha-Gal4 reporter line is recombined with the acj6 6 null mutation, GFP expression in the third antennal segment (Fig. 4B) and maxillary palps (Fig. 4F) is reduced dramatically. There was a consistently greater reduction in fluorescence of antennal neurons compared with maxillary palp neurons, suggesting that different regulatory machinery for cholinergic expression may exist in these two olfactory sensory organs. Interestingly, the second antennal segment mechanosen- sory chordotonal neurons, associated with Johnston's organ, show normal fluorescence in $a c j 6^{6}$ mutants (Fig. 4B). Expression of the cholinergic locus in the neurons of the second antennal segment thus does not depend on acj6.

We also genetically recombined the $7.4 \mathrm{~kb}$ Cha-Gal4 cholinergic reporter line with a strong lozenge mutant allele $l z^{3}$. The $l z$ gene encodes a $\mathrm{Zn}$ finger transcription factor important for the development of eyes (Daga et al., 1996; Flores et al., 1998, 2000) and olfactory organs (Riesgo-Escovar et al., 1997a,b). In $l z^{3}$ mutants, the basiconic sensilla, one of the three different types of olfactory sensilla, are missing from the third antennal segment and the maxillary palps (Lienhard and Stocker, 1991; Ray and Rodrigues, 1995) because these structures, including their associated neurons, fail to develop. Cholinergic fluorescence in antennae from $l z^{3}$ mutant males (Fig. $4 C$ ) shows an even greater loss of fluorescence than that seen in $a c j 6^{6}$ mutants. Maxillary palp fluorescence is also significantly reduced in $l z^{3}$ mutants (Fig. 4G). The antennae and maxillary palps from $l z^{3}$ mutants are smaller than wild type, and the decrease in cholinergic fluorescence can be explained by the complete loss of basiconic sensilla, including their associated cholinergic neurons (Lienhard and Stocker, 1991; Ray and Rodrigues, 1995).

Our previous characterization of the cholinergic locus regulatory DNA indicated that $1.2 \mathrm{~kb}$ of $5^{\prime}$ flanking sequence was not sufficient to drive reporter gene expression in PNS olfactory neurons (Kitamoto et al., 1995). We confirmed this by constructing $1.2 \mathrm{~kb}$ Cha-Gal4 driver lines and observing fluorescence in antennae and maxillary palps when recombined with a UAS-GFP responder line. Nearly all fluorescence is lost from the third antennal segment (Fig. 4D) or maxillary palps (Fig. $4 H$ ) in a wild-type genetic background. The cholinergic locus $5^{\prime}$ flanking DNA thus contains an important positive regulatory element(s) required for expression in olfactory neurons that are upstream of the proximal $1.2 \mathrm{~kb}$ of $5^{\prime}$ flanking DNA.

Insect antennal lobes are the primary olfactory association centers in the CNS and can be subdivided into structural units termed glomeruli (Homberg et al., 1989; Boeckh and Tolbert, 1993). Glomeruli are neuropile regions made up of axon projections of olfactory neurons originating in the third antennal segment and maxillary palps along with antennal lobe interneuron projections (Stocker et al., 1983; Gao et al., 2000). Drosophila antennal lobe neuropile, primary olfactory neurons, and antennal lobe interneurons are all enriched in cholinergic elements (Yasuyama et al., 1995; Salvaterra and Kitamoto, 2001). We examined the cholinergic fluorescence in antennal lobes of $a c j 6^{6}$ and $l z^{3}$ mutants and compared the patterns with wild type as shown in Figure 5. As expected, we saw a dramatic reduction of cholinergic fluorescence in subsets of glomeruli in the antennal lobes of both mutants. The decreased cholinergic fluorescence in $a c j 6^{6}$ mutant antennal lobes is likely to result entirely from the decreased fluorescence in primary olfactory cholinergic neurons because the fluorescent population of cholinergic antennal lobe interneurons appears similar to that of wild type (Fig. $5 A, B$ ). In contrast, the decrease in $l z^{3}$ antennal lobe cholinergic fluorescence is a result of both a loss of olfactory neurons and a decrease in fluorescent antennal lobe interneurons (Fig. 5C). We do not know whether the normal population of cholinergic antennal lobe interneurons is missing in $l z^{3}$ mutants or whether the neurons are present but fail to express the reporter gene.

Acj6 is expressed during all developmental stages of Drosophila (embryo, larval, pupal, and adult) (Treacy et al., 1991; 

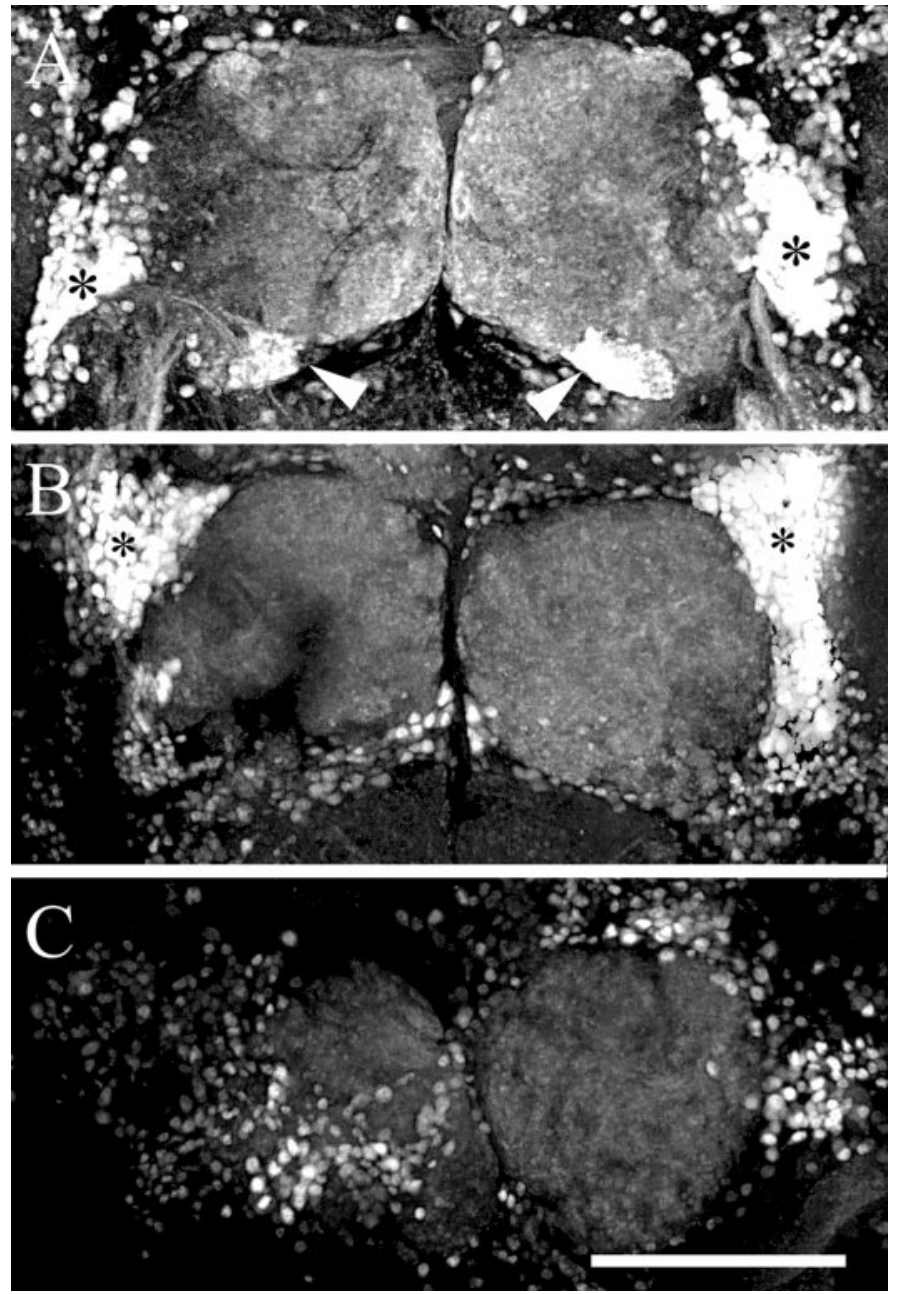

Figure 5. Cholinergic neuropile fluorescence is decreased in antennal lobes of $a c j 66^{6}$ mutant males. Brains were dissected from the heads of adult male flies containing the $7.4 \mathrm{~kb}$ Cha-Gal4/UAS-GFP fluorescent cholinergic reporter gene system and imaged using confocal microscopy. Stacks of $\mathrm{Z}$ sections were collected, and 2D projections were constructed to provide an extended depth of focus. $A$, The pattern of cholinergic fluorescence in wild-type flies. Several antennal lobe glomeruli show high levels of cholinergic fluorescence made up of a combination of elements projecting from the primary olfactory neurons of the third antennal segments and maxillary palps as well as the projections of fluorescent cholinergic antennal lobe interneurons (*). The arrowheads indicate the roots of the antennal nerves. $B$, Fluorescence of antennal lobe glomerular structures in $a c j 6^{6}$ mutant males is less distinct, probably caused by the reduction or absence of cholinergic fluorescence in primary olfactory neurons, because the fluorescence of the antennal lobe cholinergic interneurons appears relatively normal. Note the absence of fluorescence in the antennal nerve root. $C$, The antennal lobe fluorescence pattern is absent or very indistinct in $l z^{3}$ mutant brain. Glomerular organization of fluorescence is not visible, and the number of fluorescent antennal lobe interneurons is dramatically reduced. All antennal lobes are viewed from the anterior with dorsal up. Scale bar, $50 \mu \mathrm{m}$.

Turner 1996), and larvae exhibit defective olfactory behavior (Ayer et al., 1991). We evaluated the pattern of cholinergic fluorescent reporter gene expression in the larval olfactory organ, the antennomaxillary complex (AMC) (Park et al., 1997). As shown in Fig. 6, the strong cholinergic GFP expression in wild-type $\mathrm{AMC}$ neurons is significantly reduced in $a c j 6^{6}$ mutants. Acj6 function is thus also necessary for larval olfactory expression of the cholinergic locus.
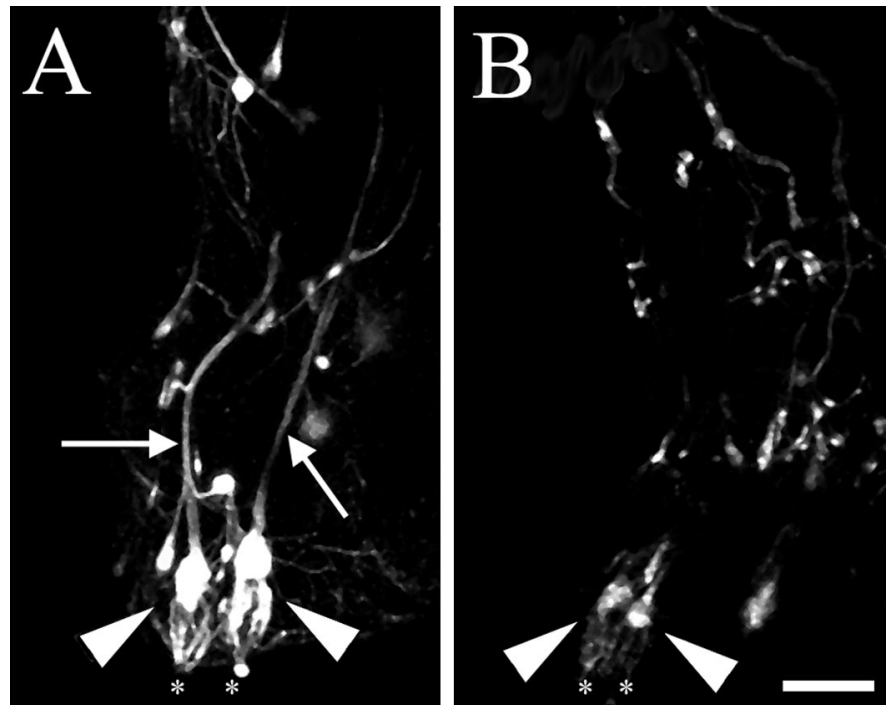

Figure 6. Cholinergic neuron fluorescence is decreased in larval primary olfactory neurons from acj6 $6^{6}$ mutants. Whole intact male third instar larvae containing the $7.4 \mathrm{~kb}$ Cha-Gal4/UAS-GFP fluorescent cholinergic reporter gene system were imaged using wide-field fluorescence microscopy. Stacks of $\mathrm{Z}$ sections were collected, and $2 \mathrm{D}$ projections were constructed to provide an extended depth of focus. $A$, Cholinergic fluorescence is observed in neurons of the antennomaxillary complex of wild-type larvae (arrowhead) as well as neurons associated with external sensory organs. Individual neurons are obscured by the intensity of fluorescence in the antennomaxillary complex. Note that the dendrites extending into the dorsal organ (*) are visible, as well as the antennal nerve (arrow). B, The cholinergic fluorescence is decreased significantly in antennomaxillary complex neurons of $a c j 6^{6}$ larvae (arrowhead). Other fluorescent cholinergic neurons (associated with external sensory organs) appear relatively normal. Larvae are viewed from the dorsal surface with anterior at the bottom. Scale bar, $40 \mu \mathrm{m}$.

\section{Acj6 binds to a specific motif present in the cholinergic regulatory DNA}

Acj6 function is necessary for the normal expression of the cholinergic locus and may act either directly, as a transcriptional regulator of the locus, or indirectly, through regulation of other intermediate genes. We next studied the interaction of Acj6 protein with putative binding sites in the cholinergic locus $5^{\prime}$ flanking DNA. No direct DNA binding motifs in regulatory elements are known for Drosophila Acj6 protein. Acj6, however, is a homolog of the vertebrate class IV POU proteins of the Brn3 family and contains a POU specific domain and a POU homeodomain with extensive homology to Brn3a, b, and c (Gerrero et al., 1993; Xiang et al., 1993). Because Brn3 DNA binding motifs have been studied extensively (Turner et al., 1994), we scanned the cholinergic locus 5' flanking DNA for similar motifs. Initially we concentrated on a region of the cholinergic locus 5' flanking DNA known to be important for expression in peripheral sensory olfactory neurons (Kitamoto et al., 1995). This region is in the distal part of a $3.3 \mathrm{~kb}$ DNA fragment because deletion of the 5' flanking DNA to $1.2 \mathrm{~kb}$ eliminates reporter gene expression in olfactory neurons (Kitamoto et al., 1995) (Fig. 4D,H). It is likely, therefore that any direct interaction of Acj6 protein with cholinergic regulatory DNA important for olfactory neuron expression will be localized upstream of the $1.2 \mathrm{~kb} \mathrm{5}$ flanking DNA. We identified seven candidate binding motifs (designated $\mathrm{A}-\mathrm{G})$ (Fig. $7 A$ ) on the basis of the fact that they contained either of two core elements (ATAATT or ATAAAT) identified in the two known Brn3 binding motifs, ATAATTAAT (Gruber et al., 1997) and 


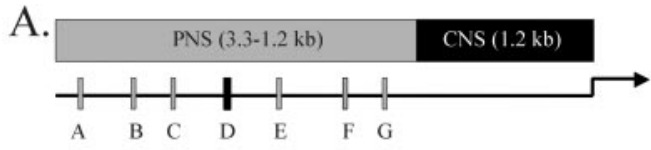

B.

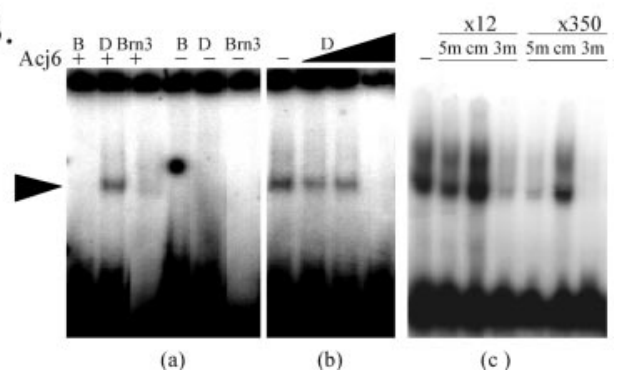

Figure 7. Acj6 protein binds to a motif in the $5^{\prime}$ flanking DNA of the cholinergic locus. Shown is a schematic drawing of the $\sim 3.3 \mathrm{~kb}$ of $5^{\prime}$ flanking DNA upstream of the Drosophila cholinergic locus. Regulatory elements necessary for CNS specific expression are located in the proximal $1.2 \mathrm{~kb}$ of $5^{\prime}$ flanking DNA (black), whereas those necessary for expression in PNS olfactory neurons are thought to be located in the distal part (3.3-1.2 kb; gray). The relative positions of the seven different motifs tested for their ability to bind recombinant Acj6 protein are indicated as small boxes along the line. Motifs that did not bind Acj6 protein are shown in gray, and positive motif $\mathrm{D}$ is indicated in black. The arrow indicates the transcription start site for the locus. $B$, Electrophoretic gel mobility shift assay. Synthetic oligonucleotides complementary to seven different $19-22$ base sequences were end labeled with ${ }^{32} \mathrm{P}$ and tested for binding to recombinant Acj6 protein containing the POU homeodomain and POU specific domain responsible for DNA recognition. Only motif D (GACTTGAATAAATTAAAACTTT) showed a shifted band indicated by the arrowhead [(a), lane 2]. Motif B (ATAAGACATAATTGACAATGGA) is included on the same gel as an example of the six negative motifs tested (lane 1). A consensus Brn3.0 motif (TGCATAATTAATTAC) was also tested as a positive control. The shifted band is weaker than that seen for motif $\mathrm{D}$ and appears to run slightly faster (lane 3 ). No bands were shifted when Acj6 protein was eliminated from the reaction (lanes 4, 5, and 6 ). In (b), ${ }^{32} \mathrm{P}$-labeled motif D binding to Acj6 can be competitively inhibited by addition of increasing amounts of unlabeled oligonucleotide $(0 \times, 0.4 \times, 4 \times$, or $40 \times$ fold concentration). Panel (c) shows that clustered point mutations introduced into the core residues of motif D ( $\mathrm{cm}$, GACTTGAACGGGCCAAAACTTT, underlined base changes) lose their ability to compete with ${ }^{32} \mathrm{P}$-labeled motif D. In contrast, changes in the $5^{\prime}$ flanking bases $(5 m$, TGACCTAATAAATTAAAACTTT or the $3^{\prime}$ flanking bases (3m, GACTTGAATAAATTAAGGACCC) retain the ability to compete with ${ }^{32} \mathrm{P}$-labeled motif D. Mutant oligonucleotides were tested at $12 \times$ and $350 \times$ molar excess.

GCATAAATAAT (Thompson et al., 1987; Gerrero et al., 1993; Turner et al., 1994). Nineteen to twenty-two base oligonucleotides, representing these core sequences along with their flanking bases, were synthesized and tested for their ability to bind recombinant Acj6 protein. Only motif D showed strong specific binding with Acj6 recombinant protein as shown in Figure $7 B(a)$. Figure 7 also shows the absence of Acj6 binding to motif B, which is representative of the six negative sites tested. Specificity of Acj6 binding to motif $\mathrm{D}$ was established by competitive inhibition using unlabeled oligonucleotide [Fig. $7 B(b)]$ and tested further by constructing clustered point mutations in the target oligonucleotide D [Fig. $7 B(c)$ ]. As expected, binding was abolished when the core sequence was mutated [Fig. $7 B(c), c m]$. Mutations introduced into the $5^{\prime}$ or $3^{\prime}$ flanking bases of motif $\mathrm{D}$ have little or no effect on Acj6 binding [Fig. 7B(c)]. These results show that Acj6 protein can interact directly with a specific site in the cholinergic locus regulatory DNA and suggest that Acj6 may function as a direct transcriptional regulator of the cholinergic locus in peripheral sensory olfactory neurons.

\section{Transgenic expression of Acj6}

We have used the Gal4 expression system (Brand and Perrimon, 1993) to investigate whether transgenic overexpression of Acj6 in wild-type flies is sufficient to increase expression of the cholinergic locus. Transgenic lines carrying a UAS responder gene coding for either of two different Acj6 isoforms were tested (Certel et al., 2000). The isoforms differ primarily by the absence [UAS-acj6 $(1,4)]$ or presence $[\operatorname{acj} 6(1,3,4)]$ of an exon 3 coding for POU IV box characteristic of this class of POU domain genes (Herr and Cleary, 1995; Latchman, 1999; Certel et al., 2000). Expression either was driven in all of the cholinergic neurons by recombination with the $7.4 \mathrm{~kb} C h a-G a l 4$ driver or was restricted to olfactory neurons by recombination with the GH86-Gal4 driver (Heimbeck et al., 1999). ChAT activity was measured in recombinants, and the results are presented in Table 1. Gal4 driver-dependent expression of UAS-Acj6 isoforms was confirmed by RT-PCR analysis (data not shown). Expression of the Acj6 $(1,3,4)$ isoform in all types of cholinergic neurons resulted in a small but statistically significant increase in ChAT activity $(\sim 10 \%)$. Surprisingly, expression of the Acj6 $(1,4)$ isoform with the same cholinergic driver resulted in third instar larval or late pupal lethality. The reason for lethality is unknown but may be related to misregulation of the cholinergic locus (or other genes) in cholinergic neurons. The same Acj6 $(1,4)$ isoform has been shown to inhibit terminal branching and synapse formation when ectopically expressed in motor neurons (Certel et al., 2000). When expression of either Acj6 isoform is restricted to antennal and maxillary palp olfactory neurons using the GH86-Gal4 driver, we observed no significant changes in ChAT activity (Table 1). These results suggest that overexpression of these two Acj6 isoforms in cholinergic olfactory neurons is not sufficient to alter expression of the cholinergic locus in olfactory neurons but may be able to alter expression in a population of unidentified cholinergic neurons. In addition, there is a clear difference in the function of Acj6 isoforms when they are over or misexpressed in all cholinergic neurons.

\section{DISCUSSION}

\section{Acj6 function is necessary for proper expression of the cholinergic locus in primary olfactory neurons}

The principal conclusion of this study is that the Drosophila class IV POU domain transcription factor Acj6 is required for normal expression of the cholinergic gene locus in primary olfactory neurons. Evidence supporting this conclusion comes primarily from genetic experiments demonstrating a reduction in cholinergic locus expression in animals carrying mutations in the acj6 gene. We have documented a decrease in ChAT enzyme activity and protein, a substantial decrease in antennal ChAT-specific mRNA, and a loss of fluorescent cholinergic reporter gene expression in olfactory neurons of antennae and maxillary palps of acj6 mutants. The decrease in cholinergic locus expression is proportional to the level of Acj6 function because ChAT activity is decreased more in an $a c j 6^{6}$ null genetic background than in an acj6 ${ }^{1}$ hypomorphic background (Clyne et al., 1999a) (Fig. 1). The reduction of ChAT mRNA in antennae from $a c j 6^{6}$ mutants (Fig. 2 ) is consistent with a decrease in transcription. The decrease in locus expression is not complete because some residual fluorescence is observed in antennal, maxillary palp neurons as well as in larval and embryonic (data not shown) olfactory neurons. 
Table 1. Transgenic expression of different Acj6 isoforms

\begin{tabular}{|c|c|c|c|}
\hline Driver & Responder & $\begin{array}{l}\text { ChAT activity (\% of } \\
\text { control } \pm \text { SEM })^{a}\end{array}$ & $t$ test $^{b}$ \\
\hline Cha-Gal4 (III) ${ }^{c}$ (two copies) & UAS-Acj6 $(1,3,4)$ (II) (two copies) & $110.0 \pm 0.6$ & $p<0.0001$ \\
\hline Cha-Gal4 (II) ${ }^{d}$ & UAS-Acj6 $(1,4)$ (III) & Lethal $^{e}$ & NA \\
\hline GH86-Gal4 (X) & UAS- $A c j 6(1,3,4)$ & $97.0 \pm 2.2$ & $p>0.4$ \\
\hline \multirow[t]{3}{*}{ GH86-Gal4 (X) } & UAS-Acj6(1,4) & $94.3 \pm 1.7$ & $p>0.2$ \\
\hline & UAS-Acj6 $(1,3,4)$ (two copies) & $103.2 \pm 4.8$ & $p>0.7$ \\
\hline & UAS-Acj6 $(1,4)$ (two copies) & $95.6 \pm 4.1$ & $p>0.6$ \\
\hline Cha-Gal4 (III) (two copies) & & $99.0 \pm 5.9$ & $p>0.6$ \\
\hline Cha-Gal4 (II) (two copies) & & $93.0 \pm 10.4$ & $p>0.9$ \\
\hline
\end{tabular}

NA, Not applicable.

${ }^{a}$ ChAT activity was assayed using five individual whole bodies of adult males (5-8 d old) for each group.

${ }^{b}$ Student's unpaired $t$ test; $n=5$.

${ }^{c} 7.4 \mathrm{~kb}$ Cha-Gal4 line 15A. Chromosomes containing the transgenes are indicated in parentheses.

${ }^{d} 7.4 \mathrm{~kb}$ Cha-Gal4 line 19B.

${ }^{e}$ All animals die during late third instar larval or early pupal stages.

Perhaps there are redundant transcriptional regulators expressed in some types of olfactory neurons, or alternatively, some types of cholinergic neurons may be only partly dependent on Acj6 for locus expression.

Acj6 does not regulate the cholinergic locus in all types of cholinergic neurons. There are at least three classes of cholinergic neurons that can be distinguished relative to Acj6 function. First are those that are dependent on Acj6, such as most primary olfactory neurons. Eighty-four of the 120 total maxillary palp olfactory neurons express Acj6 (Clyne et al., 1999a), whereas we estimate $\sim 97$ are cholinergic (data not shown) and show reduced or absent expression in $a c j 6^{6}$ mutants. Second are neurons that are independent of Acj6, such as the second antennal segment mechanosensory neurons, which do not express Acj6 and show no change in cholinergic fluorescence in $\operatorname{acj} 6^{6}$ mutants. Third are neurons that express Acj6 but maintain cholinergic expression even in $a c j 6^{6}$ mutants, such as the larval SP interneurons (Certel et al., 2000). There is also likely to be some overlap in the cholinergic central complex, antennal lobe, and optic lobe interneurons, because all of these regions have numerous Acj6positive (Certel et al., 2000) and cholinergic neurons (Yasuyama and Salvaterra, 1999). In addition, acj6 $6^{6}$ null mutants are viable (Clyne et al., 1999a), whereas loss-of-function mutations in either product of the cholinergic locus (the Cha or Vacht genes) are late embryo or early larval lethal (Greenspan, 1980; Kitamoto et al., 2000). Thus the reduction in ChAT enzyme activity, protein, mRNA, and fluorescent cholinergic reporter expression seen in acj6 mutants is likely attributed to the dependence of cholinergic locus expression on Acj6 function only in nonessential cholinergic neurons, such as the primary olfactory neurons.

Two major possibilities could account for the reduction in cholinergic fluorescence in olfactory neurons from $a c j 6^{6}$ mutants. One is a loss of olfactory cholinergic neurons themselves and the other is a loss of cholinergic reporter gene expression. Olfactory sensilla house olfactory neurons as well as associated support cells (Stocker, 1994; Riesgo-Escovar et al., 1997a,b; Clyne et al., 1999b; Vosshall et al., 1999). Mutant $a c j 6^{6}$ males show no significant sensillar phenotype and appear to contain a normal number of primary olfactory neurons (Ayer et al., 1991; Clyne et al., 1999a), making the latter possibility most likely. In addition, $l z^{3}$ mutants fail to develop neurons of basiconic sensilla, have a reduced number of trichoid sensilla (Stocker and Gendre, 1988; Stocker et al., 1993; Riesgo-Escovar et al., 1997a,b), and show a nearly complete absence of cholinergic fluorescence in their smaller olfactory organs (Fig. 4C,G). Our results indicate that cholinergic neurons are associated with these two major types of sensilla.

The AMC houses the embryonic and larval olfactory neurons (Stocker, 1994), and we see a dramatic reduction in cholinergic fluorescence in $a c j 6^{6}$ mutants (Fig. 6). Interestingly, AMC neurons are among the first to show a cholinergic fluorescence (data not shown) and are the first neurons in which Acj6 expression is detected (Certel et al., 2000). The expression of Acj6 and ChAT activity also parallels each other during embryonic development (Carbini et al., 1990; Certel et al., 2000).

\section{A reduction in cholinergic locus expression could account for acj6 6}

A decrease in expression of the cholinergic locus is likely to modify synaptic neurotransmission between the primary olfactory cholinergic neurons and the antennal lobes in the brain. This could easily explain the failure of $\operatorname{acj} 6^{6}$ mutant adults and larvae to behaviorally respond to many types of odors (Ayer et al., 1991; Certel et al., 2000). Most, but not all, odors result in abnormal behavioral responses in $a c j 6^{6}$ mutants (Clyne et al., 1999a). Perhaps the loss of cholinergic locus expression is not complete in all affected neurons, or alternatively, there could be small populations of cholinergic or noncholinergic neurons not affected by the acj $6^{6}$ mutation, because we see a small amount of residual cholinergic fluorescence in olfactory organs.

It is harder to explain the defective cellular physiology observed in primary olfactory neurons of $a c j 6^{6}$ mutants (Clyne et al., 1997; Clyne et al., 1999a), because reduced cholinergic expression may not be expected to affect the intrinsic membrane responsive properties of these neurons. Expression of a few types of olfactory receptor genes are lost in $a c j 6^{6}$ mutants (Clyne et al., 1999b). It is not known, however, whether the loss of receptor expression is a direct or indirect consequence of mutant Acj6 function. Acj6 could play a direct role by binding to regulatory sequences of particular olfactory receptor genes, but such a possibility has not been demonstrated. As an alternative explanation, disruption of synaptic transmission between cholinergic olfactory sensory neurons and the CNS could result in indirect changes in olfactory receptor gene expression through a feedback mechanism dependent on normal synaptic transmission. Such an 
activity-dependent positive feedback mechanism has been proposed to account for the loss of cholinergic expression in Drosophila temperature-sensitive mutants (Tajima and Salvaterra, 1992) and has been well documented in stress-related effects on catecholaminergic gene expression (for review, see Sabban and Kvetnansky, 2001). This type of feedback mechanism could perhaps better account for the rather extensive changes in olfactory physiology in $a c j 6^{6}$ mutants because most of the neurons are cholinergic, but individual neurons express only one or a few different olfactory receptor genes (Clyne et al., 1999a; Vosshall et al., 1999; Vosshall, 2000).

In addition to olfactory defects, acj6 mutants also show reduced locomotor activity (Certel et al., 2000). This phenotype is thought to result from defective neurons in the central complex, a region of the CNS believed to regulate locomotor function. Reduced locomotor activity is also a phenotype of Cha mutants (Greenspan, 1980), and transgenic animals expressing low levels of choline acetyltransferase activity show reduced locomotion (Kitamoto and Salvaterra, 1995; Yasuyama et al., 1995). Perhaps Acj6 is also involved in regulating cholinergic locus expression in an unidentified subset of CNS cholinergic neurons.

\section{Acj6 binds to a specific motif in the cholinergic locus 5' regulatory DNA}

We have identified a particular motif that binds recombinant Acj6 protein and thus propose that it is a direct transcriptional regulator of the cholinergic locus. This is the first reported binding motif for Acj6 present in a DNA regulatory element and confirms that it is closely related to the known binding motifs of Brn3 (Gerrero et al., 1993; Xiang et al., 1993; Turner, 1996; Gruber et al., 1997). The Acj6 binding motif is present in a position consistent with its proposed importance in regulating the locus in olfactory neurons. Cholinergic reporter gene constructs are only expressed in olfactory neurons when they contain upstream DNA sequences of $1.2 \mathrm{~kb}$ of $5^{\prime}$ flanking DNA (Kitamoto et al., 1992).

The vertebrate (Brn3 family) and nematode (UNC-86) proteins, most homologous to Acj6, are important for specifying many types of differentiated neurons and have been studied most extensively in sensory neurons (Finney et al., 1988; Gerrero et al., 1993; Xiang et al., 1993, 1997; Latchman, 1999). Although regulation of cholinergic locus expression has not been investigated directly in Brn3 or Unc-86 mutants, at least one form of Brn3 regulates expression of a particular type of nicotinic cholinergic receptor (Milton et al., 1996). Thus there may be some evolutionarily conserved aspects of cholinergic gene regulation.

Class IV POU domain transcriptional regulators have been studied extensively in vertebrates, and their versatility makes them ideally suited to regulate diverse cellular phenotypes (for review, see Schonemann et al., 1998; Latchman, 1999; Phillips and Luisi, 2000). They interact with specific but divergent DNA sequences, can activate or inhibit target genes, and can form hetero- or homomultimers. Additional versatility comes from alternatively spliced isoforms. When we express the Acj6 $(1,4)$ isoform in all cholinergic neurons, the result is lethality. In contrast, expression of Acj6 $(1,3,4)$ results in a modest increase in ChAT activity. The difference between these isoforms is the presence of exon 3 in the latter, which contributes to the structure of the characteristic POUIV box (Certel et al., 2000). This result emphasizes the differential functional activity provided by the POU IV box (Morris et al., 1994; Turner t al., 1994; Certel et al., 2000). It is also likely that the increase in ChAT activity seen with the Acj6 $(1,3,4)$ isoform is not restricted to olfactory cholinergic neurons because the olfactory neuron-specific GH86-Gal4 expression did not increase cholinergic locus expression. Other unknown regulatory factors may thus be necessary to positively regulate cholinergic locus expression in olfactory neurons. Perhaps these are non-DNA binding coregulators such as those known to help establish their specificity and transcriptional readout of vertebrate POU domain proteins (Latchman, 1999). Interestingly, besides Acj6, two other Drosophila POU transcriptional regulators have been implicated in neurotransmitter phenotype specification (Johnson et al., 1989; Johnson and Hirsh, 1990; Kitamoto and Salvaterra, 1995). Future studies in Drosophila and other species will be required to identify other neurotransmitterrelated genes regulated by POU domain transcription factors and particular transcriptional coregulators necessary for their specificity.

\section{REFERENCES}

Alfonso A, Grundahl K, Duerr JS, Han HP, Rand JB (1993) The Caenorhabditis elegans unc-17 gene: a putative vesicular acetylcholine transporter. Science 261(5121):617-619.

Ayer Jr RK, Carlson J (1991) acj6: a gene affecting olfactory physiology and behavior in Drosophila. Proc Natl Acad Sci USA 88:5467-5471.

Ayer Jr RK, Carlson J (1992) Olfactory physiology in the Drosophila antenna and maxillary palp: acj6 distinguishes two classes of odorant pathways. J Neurobiol 23:965-982.

Benveniste RJ, Taghert PH (1999) Cell type-specific regulatory sequences control expression of the Drosophila FMRF-NH2 neuropeptide gene. J Neurobiol 38:507-520.

Berse B, I. Lopez-Coviella I, Blusztajn JK (1999) Activation of TrkA by nerve growth factor upregulates expression of the cholinergic gene locus but attenuates the response to ciliary neurotrophic growth factor. Biochem J 342:301-308.

Boeckh J, Tolbert LP (1993) Synaptic organization and development of the antennal lobe in insects. Microsc Res Tech 24:260-280.

Brand AH, Perrimon N (1993) Targeted gene expression as a means of altering cell fates and generating dominant phenotypes. Development 118:401-415.

Carbini LA, Muno Zmaines VJ, Salvaterra PM (1990) Developmental expression of choline acetyltransferase mRNA in Drosophila. Neurochem Res 15:1089-1096.

Certel SJ, Clyne PJ, Carlson JR, Johnson WA (2000) Regulation of central neuron synaptic targeting by the Drosophila POU protein, Acj6. Development 127:2395-2405.

Clyne P, Grant A, O'Connell R, Carlson JR (1997) Odorant response of individual sensilla on the Drosophila antenna. Invert Neurosci 3:127135.

Clyne PJ, Certel SJ, de Bruyne M, Zaslavsky L, Johnson WA, Carlson JR (1999a) The odor specificities of a subset of olfactory receptor neurons are governed by Acj6, a POU-domain transcription factor. Neuron 22:339-347.

Clyne PJ, Warr CG, Freeman MR, Lessing D, Kim J, Carlson JR (1999b) A novel family of divergent seven-transmembrane proteins: candidate odorant receptors in Drosophila. Neuron 22:327-338.

Daga A, Karlovich CA, Dumstrei K, Banerjee U (1996) Patterning of cells in the Drosophila eye by Lozenge, which shares homologous domains with AML1. Genes Dev 10:1194-1205.

De Gois S, Houhou L, Oda Y, Corbex M, Pajak F, Thevenot E, Vodjdani G, Mallet J, Berrard S (2000) Is RE1/NRSE a common cis-regulatory sequence for ChAT and VAChT genes? J Biol Chem 275:36683-36690.

Eberl DF, Hardy RW, Kernan MJ (2000) Genetically similar transduction mechanisms for touch and hearing in Drosophila. J Neurosci 20:5981-5988.

Erickson JD, Varoqui H, Schafer MK, Modi W, Diebler MF, Weihe E, Rand J, Eiden LE, Bonner TI, Usdin TB (1994) Functional identification of a vesicular acetylcholine transporter and its expression from a cholinergic gene locus. J Biol Chem 269:21929-21932.

Finney M, Ruvkun G, Horvitz HR (1988) The C. elegans cell lineage and differentiation gene unc-86 encodes a protein with a homeodomain and extended similarity to transcription factors. Cell 55:757-769.

Flores GV, Daga A, Kalhor HR, Banerjee U (1998) Lozenge is expressed in pluripotent precursor cells and patterns multiple cell types in the Drosophila eye through the control of cell-specific transcription factors. Development 125:3681-3687.

Flores GV, Duan H, Yan H, Nagaraj R, Fu W, Zou Y, Noll M, Banerjee $\mathrm{U}$ (2000) Combinatorial signaling in the specification of unique cell fates. Cell 103:75-85.

Fonnum F (1975) A rapid radiochemical method for the determination of choline acetyltransferase. J Neurochem 24:407-409. 
Gao Q, Yuan B, Chess A (2000) Convergent projections of Drosophila olfactory neurons to specific glomeruli in the antennal lobe. Nat Neurosci 3:780-785.

Gerrero MR, McEvilly RJ, Turner E, Lin CR, O'Connell S, Jenne KJ, Hobbs MV, Rosenfeld MG (1993) Brn-3.0: a POU-domain protein expressed in the sensory, immune, and endocrine systems that functions on elements distinct from known octamer motifs. Proc Natl Acad Sci USA 90:10841-10845.

Greenspan RJ (1980) Mutations of choline acetyltransferase and associated neural defects in Drosophila melanogaster. J Comp Physiol 137: 83-92.

Gruber CA, Rhee JM, Gleiberman A, Turner EE (1997) POU domain factors of the Brn-3 class recognize functional DNA elements which are distinctive, symmetrical, and highly conserved in evolution. Mol Cell Biol 17:2391-2400.

Hahm SH, Chen L, Patel C, Erickson J, Bonner TI, Weihe E, Schafer MK, Eiden LE (1997) Upstream sequencing and functional characterization of the human cholinergic gene locus. J Mol Neurosci 9:223-236.

Harlow E, Lane D (1988) Antibodies: a laboratory manual. Cold Spring Harbor, NY: Cold Spring Harbor Laboratory.

Heimbeck G, Bugnon V, Gendre N, Haberlin C, Stocker RF (1999) Smell and taste perception in Drosophila melanogaster larva: toxin expression studies in chemosensory neurons. J Neurosci 19:6599-6609.

Herr W, Cleary MA (1995) The POU domain: versatility in transcriptional regulation by a flexible two-in-one DNA-binding domain. Genes Dev 9:1679-1693.

Homberg U, Christensen TA, Hildebrand JG (1989) Structure and function of the deutocerebrum in insects. Annu Rev Entomol 34:477-501.

Johnson WA, Hirsh J (1990) Binding of a Drosophila POU-domain protein to a sequence element regulating gene expression in specific dopaminergic neurons. Nature 343:467-470.

Johnson WA, McCormick CA, Bray SJ, Hirsh J (1989) A neuronspecific enhancer of the Drosophila dopa decarboxylase gene. Genes Dev 3:676-686

Kitamoto T (2001) Conditional modification of behavior in Drosophila by targeted expression of a temperature-sensitive shibire allele in defined neurons. J Neurobiol 47:81-92.

Kitamoto T, Salvaterra PM (1993) Developmental regulatory elements in the 5' flanking DNA of the Drosophila choline acetyltransferase gene. Roux's Arch Dev Biol 202:159-169.

Kitamoto T, Salvaterra PM (1995) A POU homeodomain protein related to dPOU-19/pdm-1 binds to the regulatory DNA necessary for vital expression of the Drosophila choline acetyltransferase gene. J Neurosci 15:3509-3518

Kitamoto T, Ikeda K, Salvaterra PM (1992) Analysis of cis-regulatory elements in the $5^{\prime}$ flanking region of the Drosophila melanogaster choline acetyltransferase gene. J Neurosci 12:1628-1639.

Kitamoto T, Ikeda K, Salvaterra PM (1995) Regulation of choline acetyltransferase/lacZ fusion gene expression in putative cholinergic neurons of Drosophila melanogaster. J Neurobiol 28:70-81.

Kitamoto T, Wang W, Salvaterra PM (1998) Structure and organization of the Drosophila cholinergic locus. J Biol Chem 273:2706-2713.

Kitamoto T, Xie X, Wu CF, Salvaterra PM (2000) Isolation and characterization of mutants for the vesicular acetylcholine transporter gene in Drosophila melanogaster. J Neurobiol 42:161-171.

Latchman DS (1999) POU family transcription factors in the nervous system. J Cell Physiol 179:126-133.

Lienhard MC, Stocker RF (1991) The development of the sensory neuron pattern in the antennal disc of wild-type and mutant $\left(l z^{3}\right.$, ssa) Drosophila melanogaster. Development 112:1063-1075.

Lindsley DL, Zimm GG (1992) The genome of Drosophila melanogaster. San Diego: Academic.

McKenna M, Monte P, Helfand SL, Woodard C, Carlson J (1989) A simple chemosensory response in Drosophila and the isolation of acj mutants in which it is affected. Proc Natl Acad Sci USA 86:8118-8122.

Milton NG, Bessis A, Changeux JP, Latchman DS (1996) Differential regulation of neuronal nicotinic acetylcholine receptor subunit gene promoters by Brn-3 POU family transcription factors. Biochem J 317: 419-423.

Morris PJ, Theil T, Ring CJ, Lillycrop KA, Moroy T, Latchman DS (1994) The opposite and antagonistic effects of the closely related POU family transcription factors Brn-3a and Brn-3b on the activity of a target promoter are dependent on differences in the POU domain. Mol Cell Biol 14:6907-6914.

Naciff JM, Behbehani MM, Misawa H, Dedman JR (1999) Identification and transgenic analysis of a murine promoter that targets cholinergic neuron expression. J Neurochem 72:17-28.
Park Y, Caldwell MC, Datta S (1997) Mutation of the central nervous system neuroblast proliferation repressor ana leads to defects in larval olfactory behavior. J Neurobiol 33:199-211.

Phillips K, Luisi B (2000) The virtuoso of versatility: POU proteins that flex to fit. J Mol Biol 302:1023-1039.

Quinn JP, Mendelson SC (1995) Transcriptional control of neuropeptide gene expression in sensory neurons, using the preprotachykinin-A gene as a model. Can J Physiol Pharmacol 73:957-962.

Ray K, Rodrigues V (1995) Cellular events during development of the olfactory sense organs in Drosophila melanogaster. Dev Biol 167:426438.

Riesgo-Escovar JR, Piekos WB, Carlson JR (1997a) The maxillary palp of Drosophila: ultrastructure and physiology depends on the lozenge gene. J Comp Physiol [A] 180:143-150.

Riesgo-Escovar JR, Piekos WB, Carlson JR (1997b) The Drosophila antenna: ultrastructural and physiological studies in wild-type and $l o z$ enge mutants. J Comp Physiol [A] 180:151-160.

Rubin GM, Spradling AC (1982) Genetic transformation of Drosophila with transposable element vectors. Science 218:348-353.

Sabban EL, Kvetnansky R (2001) Stress-triggered activation of gene expression in catecholaminergic systems: dynamics of transcriptional events. Trends Neurosci 24:91-98.

Sacchetti P, Brownschidle LA, Granneman JG, Bannon MJ (1999) Characterization of the 5'-flanking region of the human dopamine transporter gene. Brain Res Mol Brain Res 74:167-174.

Salvaterra PM, Kitamoto T (2001) Drosophila cholinergic neurons and processes visualized with Gal4/UAS-GFP. Gene Exp Patterns 1:73-82.

Schonemann MD, Ryan AK, Erkman L, McEvilly RJ, Bermingham J, Rosenfeld MG (1998) POU domain factors in neural development. Adv Exp Med Biol 449:39-53.

Siddiqi O (1983) Olfactory neurogenetics of Drosophila. New Delhi: Oxford and $\mathrm{IBH}$

Stocker RF (1994) The organization of the chemosensory system in Drosophila melanogaster: a review. Cell Tissue Res 275:3-26.

Stocker RF, Gendre N (1988) Peripheral and central nervous effects of lozenge ${ }^{3}$ a Drosophila mutant lacking basiconic antennal sensilla. Dev Biol 127:12-24.

Stocker RF, Singh RN, Schorderet M, Siddiqi O (1983) Projection patterns of different types of antennal sensilla in the antennal glomeruli of Drosophila melanogaster. Cell Tissue Res 232:237-248.

Stocker RF, Gendre N, Batterham P (1993) Analysis of the antennal phenotype in the Drosophila mutant lozenge. J Neurogenet 9:29-53.

Tajima Y, Salvaterra PM (1992) Positive and negative feedback regulation of choline acetyltransferase mRNA levels in Drosophila: a study using temperature-sensitive mutants and embryo cell cultures. Mol Brain Res 13:213-221.

Thompson RC, Seasholtz AF, Herbert E (1987) Rat corticotropinreleasing hormone gene: sequence and tissue-specific expression. Mol Endocrinol 1:363-370.

Treacy MN, He X, Rosenfeld MG (1991) I-POU: a POU-domain protein that inhibits neuron-specific gene activation. Nature 350:577-584.

Turner EE (1996) Similar DNA recognition properties of alternatively spliced Drosophila POU factors. Proc Natl Acad Sci USA 93:1509715101.

Turner EE, Jenne KJ, Rosenfeld MG (1994) Brn-3.2: a Brn-3-related transcription factor with distinctive central nervous system expression and regulation by retinoic acid. Neuron 12:205-218.

Usdin TB, Eiden LE, Bonner TI, Erickson JD (1995) Molecular biology of the vesicular ACh transporter. Trends Neurosci 18:218-224.

Vosshall LB (2000) Olfaction in Drosophila. Curr Opin Neurobiol 10: $498-503$.

Vosshall LB, Amrein H, Morozov PS, Rzhetsky A, Axel R (1999) A spatial map of olfactory receptor expression in the Drosophila antenna. Cell 96:725-736.

Xiang M, Zhou L, Peng YW, Eddy RL, Shows TB, Nathans J (1993) Brn-3b: a POU domain gene expressed in a subset of retinal ganglion cells. Neuron 11:689-701.

Xiang M, Gan L, Li D, Zhou L, Chen ZY, Wagner D, O’Malley Jr, BW., Klein W, Nathans J (1997) Role of the Brn-3 family of POU-domain genes in the development of the auditory/vestibular, somatosensory, and visual systems. Cold Spring Harb Symp Quant Biol 62:325-336.

Yasuyama K, Salvaterra PM (1999) Localization of choline acetyltransferase-expressing neurons in Drosophila nervous system. Microsc Res Tech 45:65-79.

Yasuyama K, Kitamoto T, Salvaterra PM (1995) Immunocytochemical study of choline acetyltransferase in Drosophila melanogaster: an analysis of cis-regulatory regions controlling expression in the brain of cDNA-transformed flies. J Comp Neurol 361:25-37. 